\title{
Enhancing Social Work Research Education Through Research Field Placements
}

Jennifer A. Hewson, PhD, University of Calgary, Canada Christine A. Walsh, PhD, University of Calgary, Canada Cathryn Bradshaw, PhD, University of Calgary, Canada

\begin{abstract}
The increase focus on the role of research in the social service sector, pressure for practitioners to engage in research and the demand for integration of research and practice challenges faculties about ways in which to engage social work students in research. This paper evaluates a research based practicum program within a social work faculty at one Canadian university aimed at meeting this need. The objectives of the practicum include providing opportunities to integrate research theory/methods with practice; develop a broad range of research knowledge and skills; reduce negative stereotypes; instill passion and excitement for research; and connect students with agencies to engage in community based research. The mixed methods evaluation of the practicum included semi-structured qualitative interviews with former and current directors $(n=2)$; an online survey with past practicum students ( $n=15)$; and a pre- and post-test attitude/skills assessment, a self reflection journal exercise, and a focus group with students currently in practicum ( $n=7)$. Findings suggest benefits of the research practicum across stakeholders as well as several challenges and opportunities for program enhancement. Research practicum is an innovative way of engaging students in applied research which can augments research capacity, mitigate negative stereotypes about research, and better prepare future social work practitioners.
\end{abstract}

Keywords: research practica, research education, field education, social work education

\section{INTRODUCTION}

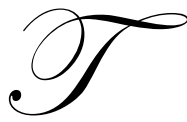

he social service sector refers to agencies or organizations providing services and programs designed to enhance social justice and well-being for individuals and communities with a particular focus on vulnerable or marginalized populations (e.g., homeless individuals, at-risk youth, isolated seniors, abuse victims, children in foster care). Recently, there has been an increased focus on the role of research in this sector and pressure for practitioners to engage in research which has not been typical practice in the sector. This is a consequence of a variety of factors including the rising demand for accountability to the profession, clients and funders (Dudley, 2009; Faulkner \& Faulkner, 2009; Grinnell \& Unrau, 2008); a greater emphasis placed on evidence based practice (Corcoran, 2000; Cournoyer, 2004; Gambrill, 2004; McNeece \& Thyer, 2004; Rzepnicki \& Briggs, 2004; Smith, 2004; Thyer, 2004); and the escalating complexity of social service delivery resulting in social work practice challenges that need to be addressed (Jacobson \& Rugeley, 2007). In spite of these pressures for increased research engagement, integration of research and practice is not considered to be standard practice in the social work profession (Gallagher, Cook, Tebb, \& Berg-Weger, 2003). Further substantial evidence demonstrates a lack of utilization of research in practice (Adam, Zosky, \& Unrau, 2004; Fraser, 1994; McCrystal, 2000; Rosen, Proctor, Morrow-Howell, \& Staudt, 1995).

Examining social work research education provides some insight into why there is a disjuncture between the demand for integration and the apparent failure in the uptake of research within social work practice. Negative stereotypes about research prevail among social work students and social work practitioners alike. In a review of literature, Cameron and Este (2008) identified the challenges of teaching research to social work students including students' lack of enthusiasm, high anxiety, perceived lack of importance, negative attitudes, and a disconnect 
between research and practice. Aversion to research is noted to be more prevalent in human services/social work versus other disciplines (Adam, Zosky, \& Unrau, 2004; Fair, 2007) as well as students seeing research as less important than psychology or business (Green, Bretzin, Leininger, \& Stauffer, 2001).

While the value of social work students learning about research is evident (Hardcastle \& Bisman, 2003), social work faculties are often challenged about how to engage social work students in research (Adam et al., 2004; Cameron \& Este, 2008). Examples of innovative research curricula can be found related to undergraduate and graduate courses with either a research focus (e.g., Anderson, 2002; Berger, 2002; Fair, 2007; Hyde \& Meyer, 2004; Stark \& Cohen, 2007; Walsh, Rutherford, \& Sears, 2010; Whipple, 2001) and practice focus (e.g., Holley, RisleyCurtiss, Stott, Jackson, \& Nelson, 2007). Hardcastle and Bisman (2003) provide an overview of various innovations in teaching social work research grouping them according to combining technology and research, group learning, and integrating research into multiple curriculum areas.

The value of connecting research and practice in order to make research more meaningful and relevant to students has been acknowledged. Cameron and Este (2008) urge professors to integrate practical research projects into the curricula. Initiatives have focused on practice based projects to work on in a research course (Hyde \& Meyer, 2004; Whipple, 2001), including research in practice courses (Berger, 2002), community and social work practice research (Coulton, 2005), and service learning as part of a research course (Knee, 2002). Very little research however, discusses ways in which field education and research could be integrated in an effort to provide opportunities for students to enhance their research capacity while working on actual research projects as the sole focus and for the duration of their field placement.

Walsh (1998) described a research/practice/field integration project completed by BSW students in their senior year practice course field placement. Students were required to identify a research problem in the field agency, carry out the research, and prepare a final research report. Over a two year period, 84 students explored diverse practice based topics in 40 field agencies using a variety of research designs. Students benefited from enhanced understanding of knowledge development, opportunities to relate course work to practice, and dissemination experience. Walsh (1998) identified the importance of ensuring that the research course was a corequisite to ensure that students had enough research knowledge to carry out the project. Knee (2002) described an example at one university where students were required to take their practicum and research methods course at the same time with the objective of providing a context and opportunities for conducting research tasks. Given challenges associated with this integration, the research course was redesigned to include a service learning component. Although a detailed account of this innovative course and the value of service learning is articulated, it is unclear the extent to which the original practicum placement continued to have a research component. While field education is examined, these studies provide limited guidance to field directors and research instructors seeking to develop a research practicum program for undergraduate and graduate students beyond a research course. This constitutes a considerable gap in field education practice and/or dissemination practices about such programs. Literature is needed about how to develop research based practica and the supports and barriers to such developments so that others may draw from these insights in order to offer similar research opportunities as another form of innovative social work research education.

The purpose of this mixed methods study is to describe the development, implementation, challenges, strengths and future directions of a research based practicum program located within a faculty of social work research centre in a Canadian University. This study aims to share learnings with others who might be interested in developing a research based practicum program within their institution and to contribute to the limited literature on such programs for enhancing research capacity for social work students.

\section{PRACTICUM EXPERIENCE}

The primary objectives of the practicum program are to provide opportunities to integrate research theory and methods with practice; develop a broad range of research knowledge and skills; reduce negative stereotypes and instill passion and excitement for research; prepare students for research situations they may experience as practitioners; and connect students with agencies to engage in research collaboration and research capacity building. Before placing a student, the student is interviewed by the Centre Director to determine a match between the 
student's focus area, existing research knowledge, desired research related learnings and one or more available research projects.

At the beginning of the practicum, the projects and tasks are confirmed and each student completes a learning agreement required for the field placement. Practicum projects include assisting with literature reviews, program evaluations, tool/instrument development, needs assessments, grant applications, ethics applications, preparing manuscripts and conference presentations. The overarching goal is to provide students with opportunities to work on a variety of tasks across stages of the research process, with exposure to qualitative and quantitative data collection methods and data analysis techniques. One approach that was used to structure student research activities was to complete a matrix which tasks related to various stages across diverse projects. Students were exposed to various research designs but the primary approach was on community-based research with diverse social service agencies. During the placement, students work closely with the Centre Director, other faculty members, agency representatives and other research team members.

\section{Developing The Program}

The research based practicum program is operated through the research centre, in a faculty of social work in one Canadian university. The centre has been in operation since 2001 and provides research support to faculty, students and community agencies with a focus on community-based, collaborative, and capacity building research. While paid student research assistant opportunities were available to students since the inception of the centre, the Centre Director was looking for additional ways in which to engage students in research in an effort to demystify research, demonstrate the relevance to practice and enhance student research capacity. A research based practicum program was piloted in January 2006 with one interested BSW student who approached the director about completing a research placement. With approval from the Director of Field, the Centre Director and one faculty member co-supervised the student to work on a community-based research project with the centre and a community agency. Community-based research refers to a collaborative approach to research which acknowledges the unique contributions of each partner, seeks to meaningfully involve all partners in the research process, and strives for social change through the integration of knowledge and action (Minkler \& Wallerstein, 2003). The student worked on a variety of research tasks across different stages in the research process related to the project. The pilot was so rewarding for both the student and the mentors that a decision was made to offer additional placements to both BSW and MSW students. This placement evolved into paid research assistant work as well as the student's thesis topic when she entered into the MSW program the next year.

A number of program supports related to the faculty, students and community were identified which made it possible to offer the practicum program. Key faculty based supports included having someone to champion the initiative (i.e., the Centre Director) and approval from the Dean, Associate Dean of Academic, Field Director and the Financial Officer. Existing faculty infrastructure was also important such as office space, computers, and no additional costs (other than practicum office start up) were necessary. Program supports related to students included having clearly articulated paid research assistant roles which provided guidelines and transitional opportunities; a group of students who were interested in the research practicum placements; and students who were comfortable working on a variety of different research tasks on various projects. Another key element of the program was the availability of community-based research projects (i.e., community agencies contracting the Centre to collaborate on research) and support from the partner agencies to have student assistants involved in a practicum role.

\section{Practicum Recruitment}

Following the pilot, the program was expanded to provide research based practica for both BSW and MSW students in either full or part time programs. Interest developed quickly with recruitment was facilitated through word of mouth from former practicum students, information sessions in research classes and student orientations, and a posting on the practicum information site. Each year the program expanded. In the first year, from Fall 2006 through Winter 2007, four students completed placements (3 BSW and 1 MSW). By the fall 2009, a total of 28 students (13 BSW and $15 \mathrm{MSW}$ ) had completed placements including two spring/summer placements. 
While previous research experience is an asset, it is not a requirement. The practicum are tailored to meet individual needs, building from the skill level possessed by each student - challenging those who already have certain skills and working to develop skills for those students with limited experience. The goal of supervision is to go beyond merely increasing research knowledge to instil passion and excitement and fostering confidence.

\section{METHODOLOGY}

The research was conducted in 2009 by the authors a former and current director of the practicum program and a faculty member who was a field instructor for the program. Following approval from the Conjoint Faculties Research Ethics Board, a student research assistant conducted two to three interviews with the former and current directors of the program to obtain information about why the program was developed, how it is implemented, benefits and challenges of offering the program, and future directions.

Past practicum students who completed a research practicum at the Centre between 2006 and $2008(n=15)$ were contacted by email using the Faculty of Social Work Alumni Listserve and were invited to participate in a 20 minutes anonymous online survey created using Survey Monkey. Seven of the 15 students participated (47\% response rate). The survey included five open ended questions pertaining to: reasons for choosing a research practicum; the extent to which the practicum met their learning goals; impacts of the practicum on their subsequent academic work, practicum placements and/or practice; strengths of the experience; and areas for improvement.

Seven students who were enrolled in practicum at the time of the study were invited to participate in the evaluation. At the beginning of the placement, the administrative coordinator for the centre, who was not responsible for supervision or grading the practicum students, informed them about the study and provided them with a consent form asking their permission to participate in some or all of the data collection activities. Students were asked to return signed consent forms to the administrative coordinator who securely stored them until grades were submitted so that the research team would not know who participated in the study. Pre- and post test surveys were conducted at the beginning and end of practicum with seven and four students, respectively completing the surveys. The survey included 12 open and closed ended survey questions about research confidence, application, value/utility of research, and skill development as well as a nine item research confidence scale. Students were also asked to complete a self reflection journal $(n=3)$ about their practicum experience handed in at the end of the practicum and a two hour focus group was also conducted $(n=3)$ which explored ways in which the program could be enhanced.

Qualitative data were analysed for themes across all participant groups. Quantitative data were entered into an SPSS file and descriptive statistics were compiled.

\section{FINDINGS}

When asked why they wanted to complete a research based practicum, students ( $\mathrm{n}=10$ pretest, posttest, online) identified to strengthen their research skills and develop a deeper understanding of research than could be developed in the classroom; to explore new areas and deepen their knowledge of the field; to enhance their curriculum vitae by gaining applied experience to pursue research as a career option; to improve their chances of being accepted into a Master's program; and logistical or practical reasons such as more flexibility, perceived lower stress, and convenient location. The findings of this evaluation revealed a variety of benefits for students, the Centre/Faculty and community agencies each of which are described more fully below.

\section{Stakeholder Benefits}

Students. Student benefits identified by the Centre Directors include having a unique experience compared to other practica; having the chance to participate in research projects as a learning experience and experiencing various stages of research; gaining the ability to translate theory and methods into practice by experiencing research as relevant and practical; developing an understanding of what research is about and how it gets carried out; having leadership and project management experiences; and gaining skills that will be useful in the workplace. 
Students noted that the practicum met their learning expectations, enhanced research skills and confidence, and opportunities for advancement. Students stated that the practica had exceeding their expectations; providing exposure and building skills that would be useful to them in future projects and positions; allowing experiences that were new and completely different from previous practica; making them more comfortable with research and evaluation; and encouraging the integration of theory learned in the classroom into practice situations. Written self reflections included comments about "opportunities to pursue interest areas" and gain "indepth knowledge" of different areas of practice. Students indicated that they left the practicum with a "greater understanding of research as a whole" and "gained experience in all the stages of the research cycle" by being "involved in a variety of projects". One former student articulated that the practicum was too short to become meaningfully involved in projects and that the tasks felt like "make-work projects" that made it difficult to develop a concept of the whole.

In general, students noted enhanced research skills and confidence. One student noted that he had, "learned a range of research techniques and how to apply them to social work practice in the real world", another reported having "a stronger understanding of how research influences social policy and social work practice on a daily basis".

The practicum was also identified as relevant to advancement in terms of applying for a MSW degree, more confidently meeting expectations of a graduate degree particularly for thesis students, applying for student grants, applying for a senior research based practicum in a non profit agency, and contributing to a competitive advantage in workplace. Tracking of placement outcomes by the Centre Directors also revealed that the practicum appeared to have been a stepping stone to other related opportunities for students such as being accepted into the Master's program particularly the thesis route; receiving undergraduate and graduate research awards; having opportunities to present at conferences and co-write journal articles; and being hired as research assistants within the Centre, Faculty and community.

Centre/Faculty. The practicum program provided benefits to both the Centre and the Faculty in that it enabled the Centre to further achieve its mandate of providing research support to students, and addressed the needs for skilled research assistants to work on projects. The program also fostered the provision of stable, consistent research assistance. Research practicum students are more like staff in that they are assigned to the practicum typically for 34 eight hour days per week which enables them to focus exclusively on research tasks. Many students choose to stay on with the Centre as research assistants once their practicum is complete. These factors help minimize turnover and maximize training efforts rather than hiring students on a project by project basis. The Centre also benefits financially in terms of reduced overhead which assists with achieving self sustainability and provides opportunities to work with more agencies due to the ability to offer more competitive, affordable prices.

Community. While program benefits were accrued most readily for students and the Centre/Faculty, with reduced costs for research assistant support, agencies were more able to undertake projects. Agencies also benefit through the increased research capacity for their agency by working collaboratively with faculty members and practicum students on projects as well as potential benefits through increased research capacity of future practitioners who may work in their agencies.

\section{Program Challenges And Opportunities For Enhancement}

A number of challenges and opportunities for enhancement were identified related to the nature of tasks and projects, supervision, infrastructure, alignment with practicum requirements, and human relations each of which are described more fully in the following section.

Nature of tasks and projects. A major challenge highlighted by the students was the cancellation of projects which meant that some students did not have an opportunity to experience a variety of research stages. One student noted that "projects should be more secure" to avoid situations where projects are "cancelled or cut short" leaving students feeling a lack of control over their circumstances. Students also noted that the lack of back up plans if projects fell through, the practicum reacting to crisis instead of proactively anticipating cancellation issues, slow reaction times to change a student's tasks, and having to wait too long for projects to be approved were problematic. The Centre Directors noted that not all students are able to deal with such vagueness, ambiguity and uncertainty and that the potential for projects to be terminated or delayed and contingency plans need to be clearly articulated in the initial 
interview and during the general orientation at the beginning of practicum.

Conversely challenges were noted concerning the amount of work for some students. One student stated "my workload was really intense so it would have been nice to recruit one of my classmates to help me". Another noted that greater differentiation of tasks was needed for Masters and Bachelor level practicum students. Some students expressed concerned around the timeframe of community-based research which, at times, seemed to be slow and drawn out.

The Centre Directors were challenged by the constant turnover of students as most practica are three months in duration. While two term practica are not typical, they help provide project consistency and opportunities for students to carry out tasks until completion. One strategy for enhancing consistency and continuity is to offer paid research assistant opportunities for students following their practicum placement, which is becoming increasingly common for the Centre.

Supervision. One of the primary challenge, as with non-research practica, is the time commitment for supervision of research practica including orientation, initial visits, midcourse and final evaluations, and weekly supervision. This is compounded by the fact that the Centre takes all students who are interested in a research placement regardless of previous research knowledge or experience resulting in a number of students entering the placement who require excessive amounts of support. As both BSW and MSW students are accepted adjusting expectations and using two different types of learning agreements are necessary. The primary field instructor has typically been the Centre Director with some support from other faculty mentors. As the number of students increased, it became increasingly time consuming for the Director to manage all of the students and projects in addition to other responsibilities. Delegating to faculty mentors, having combined training sessions for all research based practicum students, and group meetings helps to alleviate some of the time demands. One former student had concerns about the Director becoming "spread too thin" as the practicum program incorporates more students and emphasized that there will be a greater need for support to the Director so she can spend more time guiding and supervising students. This student also warned that if this is not achieved it may be necessary to cut back the number of students in practicum so the director can perform non-student related duties while still providing supervision. One student recommended having a student coordinator for all the practicum students who would provide all relevant group information (meetings, speakers, deadlines, email reminders) to all current students throughout the term.

Suitable fit for students. While the program accepts all students who are interested in doing a research based placement regardless of prior research experience, the Centre Directors stated that it is not suitable for all students. The placement requires students to be comfortable with ambiguity, able to work on multiple tasks across projects, highly flexible and adaptable, and able to work independently. In addition, given the variety of projects, students' interests may not match available projects perfectly and students need to be made aware of this possibility in the initial interview.

Infrastructure. Program expansion is a goal; however, the current practicum office, computers and limited space for files, books, and office supplies cannot accommodate all interested students. Students have to share computers, workspace and stagger work times. Infrastructure in terms of available research projects could also be problematic with practica expansion. Further, as community agencies increasingly desire research practica, there is the concern that there may be a shortage of students to fulfill this need.

Alignment with practicum requirements. Other challenges expressed by students and the Centre Directors were matching practicum and project timing and aligning research projects with the required objectives in the learning agreement. Emergent research designs and project timelines that did not often match the start and end dates of practicum placements resulted in students starting part way through a project or not getting to be part of the completion of a project. The learning agreement and practicum seminars were also found to be not as suitable for research based practicum students versus other leadership or clinical students. As highlighted by one former student, the current learning agreement privileges students doing "traditional" placements as opposed to those choosing research as their option. This student recommended that the Centre make the needs of students doing a research based practicum more apparent to the field office and the faculty administration in order to achieve changes to the learning agreement. 
Human relations. One final area that was identified was related to human relations. Students expressed a desire to have further opportunities to collaborate and share with other students in research based placements. The primary model of the program has been for each student to be assigned to a separate project, working individually on tasks. One student mentioned that more cohesion could be achieved by having students "working as a team" instead of on individual projects. While students had a chance to learn what others were doing during orientation at the beginning of the term, they wanted more communication with each other throughout the term. Thus, they recommended more open communication and stronger student collaboration, especially in circumstances when a project falls through. One recommendation was having students work as a team so they can seamlessly begin helping other students within a safe space to ask for help. A second recommendation was to manage the workload of all students by having a chart with the students' names, the names of their projects and the stages of the research cycle for each project. The goal would be to allow other students to see what their colleagues are doing and find out if a colleague needs help by highlighting a project with a certain color. Students also suggested more group learning where everyone has a chance to learn about a particular research technique regardless of whether it is something they will be focusing on. Monthly group training sessions have since been implemented. Involving guest speakers was also identified and is something to be considered in the future.

A stereotype, and sometimes a reality of the program, is that students spend more time behind a computer than having agency contact or face to face contact with clients. For example, one student complained about spending too much time "in front [of] a computer without much interaction with others" and finding the work to be "dry" because of that isolation. Supervision meetings and seeking support from other students were identified as ways to overcome this. While each project has an element of agency or client contact, the amount of contact varies across projects and tasks which means that some students may have more exposure than others. Also, contact with traditional clients may be limited so students need to expand their definition of clients to include other stakeholders such as funders, co-researchers, and community members. This needs to be clearly articulated to students before they begin the placement.

\section{FUTURE DIRECTIONS}

Learnings over four years of the program combined with the formal program evaluation revealed a number of future directions. Given that the number of BSW and MSW students was relatively equal in terms of completed placements, the practicum program should continue to offer placements to undergraduate and graduate students rather than just focusing on one level. Continued effort and focus needs to be placed on making the learning agreement and practicum seminars conducive to research based students. During a time of fiscal restraint and increased requirement for fiscal self sufficiency, innovative ways, other than hiring additional support staff for the Centre, need to be considered in order to alleviate some of the time demands for supervision being placed on the Centre Director. This could take the form of other faculty members being supported to allocate some of their workload to assisting with Centre projects or having a student coordinator. While the focus on projects within the Centre helps to enhance sustainability of the Centre, consideration is being given to modifying the existing program to further enhance agency research capacity and student experience. This might include joint placements where a student carries out research tasks at both an agency and the Centre or completes an agency exclusive research based placement with some research support from the Centre. Some of these variations have been piloted. Other innovative opportunities might include non-commissioned faculty or community-based research projects for students to work on within the practicum as service learning.

\section{LIMITATIONS}

The primary limitation of this study was that it was difficult to obtain feedback from students who had completed the program. It would have been helpful to learn from these former students, particularly those who have been practicing for a year or two to see if any of their research learnings have been transferred to their practice. In addition, those who did not participate may have chosen not to do so because they were not satisfied with their experience. Their perspectives would have been very insightful in order to enhance the program. 


\section{CONCLUSION}

This paper has provided an overview of the development and implementation of a research based practicum program within a social work faculty at one Canadian university. Insights about why and how the program was developed may be useful for field directors, instructors and other administrators who are exploring or currently offering research based placements in social work faculties within Canada and internationally. A number of benefits for the various stakeholders were identified suggesting support for further developing and continuing to offer a research based practicum placement. The literature suggests a need for such curriculum content and participants in this study report enhanced student's research capacity to better prepare students to address increasing demands to conduct research in their practice. The learnings, challenges and future directions identified in this study will help enhance the current practicum program and may also assist others with current or future research practicum programs. Given the limited literature on social work research practica, this paper will contribute to the literature on this topic to enhance understanding of innovative ways of engaging students in research application to enhance research capacity, mitigate negative stereotypes about research, and better prepare future social work practitioners for the reality of research as a key component of practice.

\section{AUTHRO INFORMATION}

Dr. Jennifer Hewson is an Assistant Professor in the Faculty of Social Work at the University of Calgary. Prior to this appointment, she was the Director of the Faculty's Centre for Social Work Research and Professional Development where she provided research support to faculty, students and community agencies. Her research interests include community development and engagement, student research engagement, community-based research, and enhancing research capacity for social service agencies. Dr. Hewson teaches research to undergraduate and graduate students to prepare them for being both consumers and creators of research knowledge as social work practitioners.

Dr. Christine Walsh is an Associate Professor in the Faculty of Social Work at the University of Calgary. She has a program of research concerning the epidemiology of violence across the lifespan and conducts community-based research with socially excluded populations include those affected by poverty and homelessness. She is interested in promoting student learning through innovative approaches to clinical, intraprofessional practice and experiential learning.

Dr. Cathryn Bradshaw is the Director for the Centre for Social Work Research and Professional Development, Faculty of Social Work, University of Calgary. In this role, she works with faculty, students and community agencies providing research support and developing research capacity. She brings over 20 years of research experience to this role and has used her role as supervisor of research practicum students to develop a number of research training modules and work with community agencies in developing research practica. Dr. Bradshaw's research interests include the leadership and management of collaborative research projects, community based research, and knowledge translation/mobilization.

\section{REFERENCES}

1. Adam, N., Zosky, D. L., \& Unrau, Y. A. (2004). Improving the research climate in social work curricula: Clarifying learning expectations across BSW and MSW research courses. Journal of Teaching in Social Work, $24(3 / 4), 1-18$.

2. Anderson, S. G. (2002). Engaging students in community-based research: A model for teaching social work research. Journal of Community Practice, 10(2), 71-87.

3. $\quad$ Berger, R. (2002). Teaching research in practice courses. Social Work Education, 21 (1), 347-358.

4. Cameron, P. J. \& Este, D. C. (2008). Engaging students in social work research education. Social Work Education, 27(4), 390-406.

5. Corcoran, J. (2000). Evidence-based social work practice with families: A lifespan approach. New York: Springer Publishing. 
6. Coulton, C. (2005). The place of community in social work practice: Conceptual and methodological developments. Social Work Research, 29 (2), 73-86.

7. Cournoyer, B. (2004). The Evidence-Based Social Work Skills Book. Boston: Allyn \& Bacon.

8. Dudley, J. R. (2009). Social Work evaluation: Enhancing what we do. Chicago, IL: Lyceum Books.

9. $\quad$ Fair, C. (2007). "I just want to help people, why do I need research methods?" Community-based research with human service majors. Mountain Rise, the International Journal of the Scholarship of Teaching and Learning, 1-12.

10. Faulkner, C.A. \& Faulkner, S.S. (2009). Research methods for social workers: A practice based approach. Chicago, IL: Lyceum Books.

11. Fraser, M. W. (1994). Scholarship and research in social work: Emerging challenges. Journal of Social Work Education, 30 (2), 252-266.

12. Gambrill, E. (2004). Contributions of Critical Thinking and Evidence-Based Practice to the Fulfillment of the Ethical Obligations of Professionals. In H.E. Briggs and T.L. Rzepnicki (Eds.) Using evidence in social work practice (Chap. 1). Chicago, IL: Lyceum Books.

13. Gallagher, M. B., Cook, C. A. L., Tebb, S., \& Berg-Weger, M. (2003). Practicing social justice: Community-based research, education and practice. Social Thought, 22 (2/3), 27-39.

14. Green, R. G., Bretzin, A., Leininger, C., \& Stauffer, R. (2003). Research learning attributes of graduate students in social work, psychology, and business. Journal of Social Work Education, 37, 333-341.

15. Grinnell, R. M. \& Unrau, Y. A. (2008). Social Work research and evaluation: Foundations of evidencebased practice. New York, NY: Oxford University Press.

16. Hardcastle, D. A., \& Bisman, C. D. (2003). Innovations in teaching social work research. Social Work Journal, 22 (1), 31-43.

17. Holley, L. C., Risley-Curtiss, C., Stott, T., Jackson, D. R., \& Nelson, R. (2007). “It's not scary: Empowering women students to become researchers. Journal of Women and Social Work, 22 (1), 99-115.

18. Hyde, C. A., \& Meyer, M. (2004). A collaborative approach to service, learning, and scholarship: A community-based research course. Journal of Community Practice, 12 (1/2), 71-88.

19. Jacobson, M. \& Rugeley, C. (2007). Community-based participatory research: Group work for social justice and community change. Social Work with Groups, 30 (4), 21-39).

20. Knee, R. T. (2002). Can service learning enhance student understanding of social work research? Journal of Teaching in Social Work, 22 (1/2), 213-225.

21. McCrystal, P. (2000). Developing the social work researcher through a practitioner research training programme. Social Work Education, 19 (4), 359-373.

22. McNeece, C.A. \& Thyer, B.A. (2004). Evidence-based practice and social work. Journal of Evidence Based Social Work, 1, 7-25.

23. Minkler, M. \& Wallerstein, N. (2003). Community-based participatory research for health. San Francisco: Jossey-Bass.

24. Rosen, A., Proctor, E. E., Morrow-Howell, N., \& Staudt, M. (1995). Rationales for practice decisions:

25. Variations in knowledge use by decision task and social work service. Research on Social Work Practice, 5, 501-523.

26. Rzepnicki, T.L. \& Briggs, H.E. (2004). Using Evidence in Your Practice. In H.E. Briggs and T.L. Rzepnicki (Eds.), Using evidence in social work practice (Introduction). Chicago, IL: Lyceum Books.

27. Smith, D. (2004). Social work and evidence-based practice. London: Jessica Kingsley Publications.

28. Stake, R. E. (2005). Qualitative case studies. In N. K. Denzin \& Y. S. Lincoln (Eds.), The Sage handbook of qualitative research ( $\left.3^{\text {rd }} \mathrm{Ed}\right)(\mathrm{pp} .443-466)$. Thousand Oaks, CA: Sage.

29. Stark, R. B. \& Cohen, B. E. (2007). Promoting positive student attitudes toward social work research using course web sites. Journal of Teaching in Social Work, 27 (1/2), 181-198.

30. Thyer, B. (2004). Science in Evidence-Based Social Work Practice. In H.E. Briggs and T.L. Rzepnicki (Eds.) Using evidence in social work practice (Chp. 1). Chicago, IL: Lyceum Books.

31. Walsh, J. (1998). A model for integrating research, practice and field instruction in the undergraduate curriculum. Journal of Teaching in Social Work, 17 (1/2), 49-63.

32. Walsh, C. A., Rutherford, G. E., \& Sears, A. E. (2010). Fostering inclusivity through teaching and learning action research. Action Research, 1-19.

33. Whipple, E. E. (2001). Keeping pace with current practice: A case study approach to infusing managed care principles into a research methods course. Journal of Teaching in Social Work, 21 (3/4), 53-74. 


\section{NOTES}

